\title{
Perinatal death in production animals in the Nordic countries - incidence and costs
}

\author{
Olav Østerås*1,2, Mona Solum Gjestvang ${ }^{3}$, Synnøve Vatn ${ }^{4}$ and Liv Sølverød ${ }^{5}$
}

\begin{abstract}
Address: ${ }^{1}$ Department of Production Animal Clinical Sciences, The Norwegian School of Veterinary Science, Oslo, Norway, ${ }^{2}$ Department of Cattle Health Services, TINE Norwegian Dairies, Ås, Norway, ${ }^{3}$ Department of Swine Health Services, Animalia, Oslo, Norway, ${ }^{4}$ Department of Sheep Health Services, Animalia, Oslo, Norway and ${ }^{5}$ Department of Goat Health Services, TINE Norwegian Dairies, Molde, Norway

Email: Olav Østerås* - olav.osteras@veths.no

* Corresponding author
\end{abstract}

from Perinatal Death In Domestic Animals: The 20th Symposium of the Nordic Committee for Veterinary Scientific Cooperation (NKVet) Reykjavik, Iceland. 26-27 April 2007

Published: 12 December 2007

Acta Veterinaria Scandinavica 2007, 49(SuppI I):SI 4 doi:I0.II86/I75I-0I47-49-SI-SI4

This abstract is available from: http://www.actavetscand.com/content/49/SI/SI4

(c) 2007 Østerås et al; licensee BioMed Central Ltd.

\section{Introduction}

In animal recording systems for cattle, perinatal death is divided into a) abortion: before 210 days of pregnancy (Finland) or 20 days before expected birth (Norway), b) born dead: dead calf after 210 of pregnancy (or before 20 days before expected birth) or died before 24 hours after birth, c) dead before identity marked: calves died later than 24 hours after birth, but before they are individually marked, and finally d) dead later as young calf in the preweaning age. For sheep, which have a birth season, the perinatal death is also given by stillbirth, death during indoor season and at spring pasture. Later death will be death on pasture. For goats there exist figures for abortion, stillbirth, dead before identity marked, and dead before preweaned similar to cattle. For piglets perinatal death is usually given as number of stillborn per litter, and percent dead piglets before weaning.

In horses there is scarse information on incidence of perinatal death. The incidence in this animal is therefore unknown. However, a large survey in the UK revealed the major reasons for stillbirth in horses was 38.8\% umbilical cord torsion or problems with long cord and ischemia, $13.7 \%$ intrapartum stillbirth or $9.8 \%$ associated with infections [1].

In production animals the focus should be on incidence risk, animal and farmers' welfare, and economic losses due to lost production potential. This paper will present available incidence risk for the Nordic countries and production animals. Some calculations on economic losses for some species and countries are also presented and discussed.

\section{Materials and methods}

The baseline animal populations in different Nordic countries were extracted from available publications after searching the Internet on http://www.PubMed.com. In addition data were retrieved from annual reports, websites on the Internet or personal communications with persons in the different countries. Numbers of death from different countries and different species was grouped according to available data classification.

Finally, the Norwegian economic efficiency control data for dairy production were used to identify mean and standard deviation of economic values for a pregnant heifer as well as a bull mature for slaughter. These economic suppositions were fed into an excel spreadsheet using @RISK version 4.5 (Palisade, London, UK) to estimate the total economic value of lost calves with the observed variation in $20 \%$ of the population. For economic calculations for other species and countries, an estimated mean from the best qualified suppositions was implemented. 


\section{Results \\ Cattle}

The loss of calves in the dairy cattle population in the Nordic countries is in Table 1.

From Denmark the death rate of beef cattle is reported to be $3-4 \%$ at birth and additionally $4-5 \%$ deaths in the lifespan 1 to 180 days (see Table 1 , footnote ${ }^{a}$ ). Denmark also reports a large difference between herds, and 29\% of herds have a death rate of $3.75 \%$ while $7 \%$ of herds have a death rate of more than $20 \%$. In general the death rate especially around birth is much higher for male than female calves, $8.1 \%$ and 5.3\%, respectively. From Norway the incidence of dead beef calves at birth is $4.4 \%$ out of 17,708 calvings [2]. Additionally $3.2 \%$ of the calves died from birth to 180 days of life. This comprises 779 and 542 calves, respectively. Altogether $40 \%$ of the total beef cattle population is included in the recording system in Norway. This will give a total estimated loss of beef calves at 2,000 dead calves at birth and 1,400 calves later in the first half of their year, a total of 3,400 calves.

Under Norwegian conditions the death numbers in Table 1 for dairy cattle were fed into a spreadsheet model with these suppositions: value (net revenue) of a pregnant heifer $3825 \pm 3328 \mathrm{NOK}$, meat production from bull calf $287 \pm 71 \mathrm{~kg}$, the value (net revenue) per kg meat $11.46 \pm$ $9.06 \mathrm{NOK}$. The figures estimated the loss of abortion to $6.0 \pm 3.7$ Mill NOK, dead calves at birth to $27 \pm 17$ mill NOK, dead calves before id-marked to $9.2 \pm 5.5$ Mill NOK, and later dead calves to $20.4 \pm 12.5 \mathrm{Mill}$ NOK. In total the loss of 18,000 calves in dairy production consists of a total money value of $64 \pm 39$ mill NOK. The distribution is illustrated in Figure 1. In total 64 mill NOK corresponds to 8 mill $€$.
For the beef production the corresponding figures for the loss of 3,400 calves will be $12 \pm 10$ mill NOK.

The supposition from Finland and Sweden were given at 100 per alive calf. According to Table 1 the total calf loss in Finland was 32000 calves. This will correspond to a money value of 3.2 million $€$. An income value of a bull for slaughter or pregnant heifer is estimated at $1500 €$ which gives a total loss of income at 48 million $€$. However, from this amount of money one has to take away the variable cost to compare with the Norwegian estimates given above. If the net revenue is set at $30 \%$ of the total income, this corresponding net revenue in Finland will be approximately 14 million $€$. If this estimation was done according to the death rate in Denmark, the 14 million $€$ would be 40 million $€$ and for Sweden, with an estimated loss of 16,500 calves, it would be 7.4 million $€$. Thus, the rough estimated loss of dairy calves would be 8 million $€$ in Norway, 14 million $€$ in Finland, 40 million $€$ in Denmark, and 7 million $€$ in Sweden, a total amount of approximately 70 million $€$.

\section{Sheep}

For sheep, Finland reports a sheep population of 54,000 to 56,000 ewes with 8,000 ewes more than 2 years old. These ewes had a mean 2.2 lambs (live and dead). At 2 weeks after birth the live lamb value per sheep was 2.0. This gives a total loss of 0.2 lambs per sheep or 1,600 lambs. For ewes $<2$ years old, a total number of 1,500 are within the control system. These ewes give birth to 1.7 lambs (live and dead) and have 1.6 still alive 2 weeks after birth. The loss is thus 0.1 lambs per ewe, or total 150 dead lambs. These figures correspond to $16 \%$ of the ewe population the total loss of lamb should be around 10,000 lambs.

Table I: Available figures for abortion, stillbirth and neonatal death in dairy cattle from Denmark, Finland, Norway and Sweden (\%)

\begin{tabular}{|c|c|c|c|c|c|}
\hline Country & Denmark $^{a}$ & Finland ${ }^{b}$ & Iceland $^{d}$ & Norwayc & Sweden \\
\hline Year presented & 2006 & 2005 & 2005 & 2006 & 2005 \\
\hline Calvings (n) & 586,380 & 356,064 & 24,000 & 284,778 & 392,000 \\
\hline Aborted & & $4,279(1.2)$ & $(1.1)$ & $\mathrm{I}, 708(0.6)$ & $(0.6)^{\mathrm{e}}$ \\
\hline Born dead & $45,737(7.8)$ & $16,692(4.7)$ & (II.4) & $8,043(2.8)$ & $(3.6)^{f}$ \\
\hline Dead before id & & $2,276(0.7)$ & $(0.9)$ & $2,574(0.9)$ & $?$ \\
\hline Dead $<30 d$ & $26,492(4.9)$ & & (1.5) & $\mathrm{I}, 907(0.7)$ & \\
\hline Dead I-90 d & & & & 4,359 (1.6) & $(3.1)^{g}$ \\
\hline Dead $1-180 \mathrm{~d}$ & $45,954(8.5)$ & $9,135(2.5)$ & & $5,722(2.1)$ & $(4.0)^{\mathrm{h}}$ \\
\hline
\end{tabular}

a According to figures from Landbrugsinfo, Kvæginfo nr.: I72I (19-03-2007), Irene Fisker.

b According to figures from ProAgria given by Hilppa Hietanen (29.06.2006).

c According to figures from TINE Rådgivning (Annual statistics 2006).

dEstimated according to Benjaminsson (2007) [4].

e Percentages according to Olsson et al. (1993) [5].

f Figures from Berglund et al. (2003) [6] gives $10.3 \%$ in Swedish Holstein.

$\mathrm{g}$ From Svensson et al. (2006) [7].

h From Svensson et al. (2006) [7] from I to 210 days of life. 


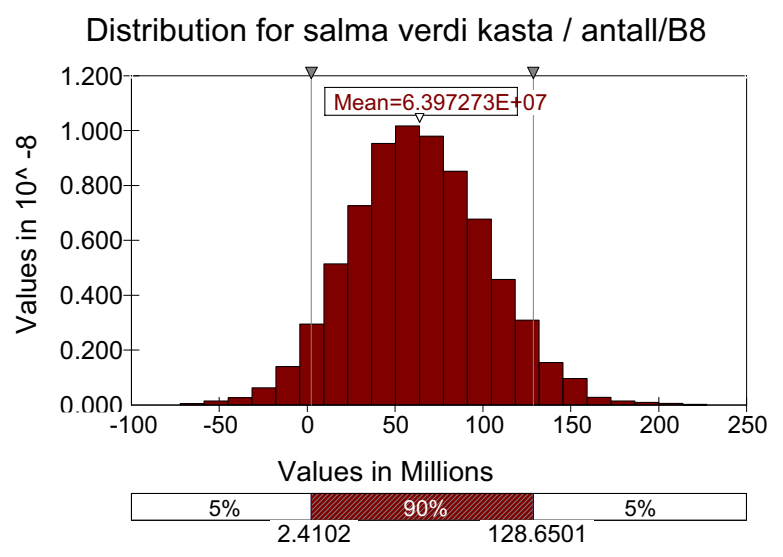

Figure I

The distribution of the estimated opportunity money value (net revenue) of 18000 calves in the Norwegian milk production system during 2006.

Norway has 303,000 ewes within the recording system. This comprises $27.8 \%$ of all sheep in 2005 . The mean lamb number per sheep was 1.95 , of these 1.87 survived. The death rate at birth is $3.97 \%$ or 0.08 per ewe. In total this would be around 24,000 lambs. The number of lambs per ewe is lower in the herds outside the recording system. Estimated for the whole country, 64,000 lambs out of at total number of 1.6 million lambs are stillborn. Additionally $3.0 \%$ is lost during the spring indoor season and $1.1 \%$ is lost during the spring pasture season. In the total population this would add up to 66,000 lambs. The total lamb loss in Norway is thus approximately 130,000 lambs. The cost of one stillbirth lamb in Norway is estimated to Norwegian krone (NOK) 1098 or in total 70 million NOK. One dead lamb on spring pasture is estimated at a cost of NOK 1176 or in total 77 million NOK. According to these estimates the total money loss for the sheep industry in Norway is about 147 million NOK [3].

Iceland has approximately 380,000 lambing ewes and 455,000 winterfeed sheep. The loss of lamb is approximately $9 \%$ out of a total of 620,000 born lambs (Sigurdur
Sigutarson, personal communication, 2007). This will make up a total loss of approximately 56,000 lambs.

\section{Goat}

The goat population in Finland has 5,000 to 6,000 female goats. No figures exist for perinatal death. Norway is the "goat country" of the Nordic countries with 33,000 goats within the recording system, which is $70 \%$ of all the goats. The total population is 47,000 goats. These goats in the recording system had $0.7 \%$ aborted kids, $2.6 \%$ dead kids at birth, $1.1 \%$ died before id-marking and $0.6 \%$ before 180 days of life. The total death rate is thus $5.0 \%$. This is a huge improvement since a period in 1990's with $2.3 \%$ abortion, 3.1\% dead kids at birth, $0.7 \%$ died before idmarking and $1.1 \%$ died before 180 days of life, a total death rate of $7.2 \%$. The reasons for the increase of abortion during the 1980's and the decrease later in 2000's are still unproved. It is extremely difficult to estimate the money value of goat kids, as many of the male kids are destroyed under the present production. If one could produce halal meat of kids, as is done in the Netherlands, the value could be estimated as for sheep app. 1000 NOK pr kid. Under supposition of 1.8 kids pr goat the total number of kids would be 85000 . A 5\% loss will comprise 4200 kids of a value of $1000 \mathrm{NOK}$, a total of $4.2 \mathrm{mill}$ NOK.

\section{Swine}

The figures for pig population, production as well as lost production due to perinatal death in the Nordic countries are listed in Table 2.

\section{Discussion}

The estimates of death given in Tables 1 and 2 and text are pretty exact according to the recorded figures given from each country. However, the economical suppositions are difficult and very preliminary. The calculation for cattle in Norway with uncertainty is an example of how it could be done. This calculation illustrates that the supposition would be different from farm to farm and also visualises the possibilities if the production is improved to the best part. However, one should be aware that not all losses due to neonatal death could or should be removed within ani-

Table 2: Piglet production and losses in the Nordic countries.

\begin{tabular}{|c|c|c|c|c|c|}
\hline Variable & Denmark & Finland & Norway & Sweden & Iceland \\
\hline Number of sows & $1,100,000$ & 161,000 & 80,000 & 160,000 & \\
\hline Farrowings/year & 2.24 & 2.10 & 2.15 & 2.2 & \\
\hline Live born/litter & 13.2 & 11.0 & 13.5 & 12.2 & \\
\hline Dead born/litter & 1.7 & 1.2 & I.I & 0.91 & \\
\hline Preweaning mortality & 14.0 & 13.0 & 14.0 & 15.4 & \\
\hline Total lost piglets & $8,156,000$ & 890,000 & 490,000 & 980,000 & \\
\hline Value per extra piglet & - & - & 580 NOK & 350 SEK & \\
\hline Total loss, mill & - & - & 283 mill NOK & 344 mill SEK & \\
\hline
\end{tabular}


mal husbandry. The reason being that many of these deaths are caused by malformation, inbreeding etc, that are supposed to be removed from the production line, or simply are to costly to correct within the frame of veterinary medicine and sound agricultural business. One should also be aware that the economic supposition is changing from country to country and from year to year. Estimation under uncertainty is a nice way to demonstrate the effects if the supposition is changing. Increased production will also influence the prices, as the market value then would decrease according to the well known price demand dependency. The calculations with economic suppositions including variability are done only for Norwegian conditions. The principles could be transferred to other countries, but not the money value. The figures on perinatal death in Norway, compared with other countries looks fairly low. Despite this, the total loss for perinatal death in production animals is estimated to be, 64 million NOK for dairy production, 12 million NOK for beef production, 147 million NOK for sheep, 4.2 million NOK for goat, and 283 million NOK for swine. This makes up a total money value of 510 million NOK or approximately 64 million $€$.

\section{Conclusion}

There is a large difference in perinatal loss within different production animals within each country as well as between countries. For example, the money loss for neonatal death in Norway is estimated to 510 million NOK or 64 million $€$. It is difficult to identify exact figures for the number of losses in different countries as well as the monetary value. For example, the total loss of calves within the dairy production is approximately 175,000 calves. Altogether $10 \%$ if these calves died in Norway and had under Norwegian supposition a money value of 64 mill NOK or 8 million $€$. One should be aware that it is impossible and not correct to imagine the total removal of this loss, however, if 10 to $25 \%$ could be saved this would be a large amount of money. There is also indication of large variation between countries, and even larger between herds.

\section{Acknowledgements}

Several persons have contributed to the information needed to prepare this paper. All these people are acknowledged: Hilppa Hietanen (cattle data) and Ulla Savolainen (sheep and goat data), and Ari Nopanen (swine data) ProAgria Association of Rural Advisory Centres, Vantaa, Finland; Børge Baustad, Barbro Mattson, Swedish Meat.

\section{References}

I. Smith KC, Blunden AS, Whitwell KE, Dunn KA, Wales AD: A survey of equine abortion, stillbirth and neonatal death in UK from I988 to 1997. Equine Vet J 2003, 35:496-50I.

2. Fagsfenteret for kjøtt: Årsmelding 2005. In Storfekjøttkontrollen Animalia, Oslo:32.

3. Animalia: $\mathbf{2}$ på kroken - et studiehefte om slaktekvalitet. Animalia, Oslo; 2006:48.

4. Benjaminsson BH: Prenatal death in Iclandic cattle. Proceeding 20th NKVet symposium, Reykjavik Iceland. 26-27 April 2007 :42-47.
5. Olsson SO, Viring S, Emanuelsson U, Jacobsson SO: Calf diseases and mortality in Swedish dairy herds. Acta Vet Scand 1993, 34:263-269.

6. Berglund B, Steinbock L, Elvander M: Causes of stillbirth and time of death in Swedish holstein calves examined post mortem. Acta Vet Scand 2003, 44: III-120.

7. Svensson C, Linder L, Olsson SO: Mortality in Swedish dairy calves and replacement heifers. Prev Vet Med 2006, 89:4769-4777. 